\title{
A EFETIVIDADE DO CONTROLE DA GESTÃO FISCAL E SUA RELAÇÃO COM AS SANÇÕES PESSOAIS IMPOSTAS AOS ADMINISTRADORES PÚBLICOS PELA LEI 10.028/2000
}

\author{
Maria Cecília Mendes Borges*
}

\begin{abstract}
1. Introdução. 2. Das inovações trazidas pela Lei 10.028/2000. 3. Da efetividade como elemento essencial para que a norma jurídica cumpra sua função na sociedade de onde ela emanou. 3.1. Da efetividade conferida ao controle da gestão fiscal pela Lei 10.028/2000 ao instituir as sançōes pessoais aos administradores públicos. 4. Considerações finais. 5. Referência bibliográfica.
\end{abstract}

\section{Introdução}

A Lei Complementar (LC) $n^{0} 101$, de 04 de maio de 2000, conhecida como Lei de Responsabilidade Fiscal - LRF, que estabelece normas sobre as finanças públicas voltadas para a responsabilidade na gestão fiscal, remete seu aspecto coativo também para normas ordinárias. Assim, foi editada a Lei 10.028, de 19 de outubro de 2000, que alterou o Decreto-Lei $n^{\circ} 2.848 / 40$ (Código Penal), a Lei n 1079/50 e o Decreto-lei $n^{\circ} 201 / 67$.

Integrando o conjunto de medidas do Programa de Estabilidade Fiscal - PEF — apresentado à sociedade brasileira em 1998, a LRF pretendia a diminuição do déficit público e a estabilização da dívida pública em relação ao PIB da economia (QUADROS e PALMIERI, 2000:IX).

E, no âmbito do Direito, em sendo uma ordem de coação, necessário o estabelecimento de uma conseqüência jurídica, a fim de conferir efetividade ao seu cumprimento por parte daqueles a quem a norma se dirige. O Direito sem a sanção

* Bacharel em Direito pela Universidade Federal de Viçosa/MG. Servidora Pública Federal do TRF/1" Região, Pós-graduanda em Direito Público pela Universidade Gama Filho/RJ em Belo Horizonte/MG.

R. Dir. Adm.,

Rio de Janeiro, 239: 89-94, Jan./Mar. 2005 
equivaleria ao fogo sem a chama ou à luz que não ilumina, pois remete à idéia do próprio Direito em si (MOTTA e FERNANDES, 2001:210).

Assim, o presente artigo objetivará o estudo de tais sanções, limitando-se às consequiências penais a serem impostas para aqueles administradores públicos que descumprirem as normas de gestão fiscal, ou seja, objetivará o estudo da dimensão pessoal, as responsabilizações possíveis em relação ao administrador público.

Pode-se falar em sanções institucionais constantes na LRF e em sanções pessoais previstas na Lei 10.028/2000, a Lei de Crimes Fiscais, segundo Marconi Braga (BRAGA, 2000:75/6) consistindo as primeiras em restrições não à pessoa responsável pelo ato irregular ou ilegal, mas à própria instituição, recaindo sobre o ente federado, ao passo que essas últimas serão aplicadas diretamente ao agente público responsável pelo ato praticado irregularmente.

Defender-se-á, no presente trabalho, que a Lei 10.028/2000, também conhecida como Lei de Crimes Fiscais, conferiu efetividade ao controle da gestão fiscal, ao estabelecer sanções pessoais ao administrador público, defendendo-se que tão somente as sanções institucionais (ou estruturais) não se prestariam a este fim.

\section{Das inovações trazidas pela Lei $10.028 / 2000$}

A Lei de Crimes Fiscais estabeleceu as sanções pessoais retro referidas, implantando a criminalização da gestão pública (CASTRO, 2001:A3). Acrescentou ao título dos crimes contra a administração pública, no Código Penal $(\mathrm{CP})$, o capítulo dos crimes contra as finanças públicas, modificando também. no mesmo título mas em capítulo anterior, o artigo que tipifica o delito de denunciação caluniosa ou investigação sem causa. Os crimes relativos às finanças públicas são todos dolosos, e o bem jurídico protegido são as finanças públicas (PRADO, 2001:808), tendo em vista que o Estado - administração pública, na maior parte delas, é o sujeito passivo do delito. Algumas se configuram em normas penais em branco, pendentes de complementação por norma de direito financeiro que fixe os limites e preencha alguns de seus conteúdos, determinando algumas de suas hipóteses.

Com referidas tipificações, a Lei tem por finalidade fazer com que não se gaste mais do que se arrecada. Teve-se em mente também a garantia da obediência ao princípio da reserva legal na execução do orçamento, pois, como defende Moreira Neto (MOREIRA NETO, 2000:82), a gestão financeira e orçamentária, como aspecto particular da administração pública, deve se submeter a tal princípio de submissão à lei do agir do administrador público, do qual é exigida a vinculação da ação. Outra finalidade de tais tipificações é impedir que o agente público subseqüente arque com dívidas suntuosas assumidas por seu antecessor sem prévia destinação de recursos para seu pagamento, ainda que tal endividamento ocorra de forma indireta, como no delito de prestação de garantia graciosa, e objetiva ainda a integridade orçamentária. Também são escopos da referida Lei o princípio da responsabilidade no uso do dinheiro público, a gestão responsável, isso porque o desvio fiscal ocorria porque a receita era prevista em patamares irreais, sancionando despesas sem lastro financeiro (TOLEDO JR. e ROSSI, 2001:932). 
Algumas condutas tipificadas são dotadas de sanções mais severas, diante de sua gravidade, tais como a assunção de obrigação no último ano do mandato ou legislatura, que perpetua seus efeitos danosos para além do mandato ou legislatura do agente, a ordenação de despesa não autorizada, conduta que é lesiva à moralidade e probidade administrativa, e o aumento de despesa total com pessoal no último ano do mandato ou legislatura, que infringe o orçamento, lesa o patrimônio público e põe em risco o equilibrio das contas da administração de seu sucessor.

A Lei 10.028/2000 também redesenhou o Decreto-lei 201/67, adequando-o ao código de gestão fiscal previsto na LRF. Foram tipificadas novas modalidades infracionais às quais poderão se sujeitar os Prefeitos municipais e aqueles que com eles praticarem tais atos.

Também foram introduzidos, pela Lei dos crimes contra as finanças públicas, condutas tipificadas como crimes de responsabilidade na Lei 1.079/50.

O direito penal é importante para a disciplina social. Entretanto, o arsenal punitivo confrontado com nossa realidade brasileira (sistema judiciário e de execução penal) pode frustrar, no tocante à efetivação e materialização de sanções penais aplicáveis, mesmo porque as sanções pessoais de maior repercussão acabam não sendo aquelas para as quais se prevê pena privativa de liberdade. Assim, por fim a Lei 10.028/2000 previu mais uma sanção para o administrador público, porém de cunho administrativo, unicamente pecuniária, que infringir seu artigo $5^{\circ}$, cujas infrações são punidas com multa de trinta por cento dos vencimentos anuais do agente que lhe der causa, sendo o pagamento da multa de sua responsabilidade pessoal.

Assim, pode-se afirmar que às condutas fiscais correspondem sanções de caráter pessoal geradoras de um verdadeiro aparato sancionatório da LRF, criando-se verdadeiro Código de Gestão Fiscal ou Código Fiscal (SANTANA, 2001:63).

Tal aparato normativo não será o redentor de todos os males, mas certo é que não há mais lugar para aventuras na frente da administração, devendo o país deixar de ter governantes tradicionais para gerentes dos interesses populares.

\section{Da efetividade como elemento essencial para que a norma jurídica cumpra sua função na sociedade de onde ela emanou}

Adotando-se como marco teórico do elemento efetividade o conceito esboçado por Tercio Sampaio (FERRAZ JÚNIOR, 1994:198), tem-se que "uma norma se diz socialmente eficaz quando encontra na realidade condições adequadas para produzir seus efeitos".

\subsection{Da efetividade conferida ao controle da gestão fiscal pela Lei 10.028/2000 ao instituir as sançōes pessoais aos administradores públicos}

A LRF fará com que o Estado caiba dentro de seu orçamento, livrando-se a administração pública brasileira de seus vícios de desperdício e corrupção. Assim, "realizando gastos e contraindo dívidas prudentemente, podem-se gerar reservas nas épocas de bonança, compensadas nas épocas de crise, evitando a falência fiscal" (QUEIROZ, 1999:27). 
Assim, a despeito de todos os benefícios e recursos trazidos ao ordenamento jurídico brasileiro pelo Código Fiscal, sua efetividade estaria abalada se não houvesse a criminalização pessoal dos agentes públicos que praticaram a conduta infracional. Assim, "se se não cumprir a lei pelos próprios comandos e conteúdos do que nela se contém. cumprir-se-á pela intimidação de suas normas e até pela final responsabilização pessoal do agente público" (CASTRO. 2001:134). Ainda segundo Cid Heraclito Queiroz (QUEIROZ, 2001:54), a sanção é que torna eficaz a LC $n^{\circ} 101$. tendo em vista as penas para as infrações às suas disposições.

Duas questões por fim merecem atenção: a despeito de todas as novas figuras delitivas, com previsão de sanções pessoais, o arsenal punitivo, quando confrontado com a realidade brasileira dos sistemas judiciário e de execução penal, pode ser frustrado, no tocante à efetivação e materialização de sanções penais aplicáveis, mesmo porque as sanções pessoais de maior repercussão acabam não sendo aquelas para as quais se prevê pena privativa de liberdade, tendo em vista ainda que quase todas as penas comportam submissão ao juizado especial criminal, com o benefício da suspensão do processo, ou penas alternativas (restritivas), multa substitutiva, sursis (suspensão condicional da pena), e o fato ainda de que muitas vezes não se consegue fazer cumprir o regime prisional legal de cumprimento de pena, devido à carência estrutural.

A outra questão é que, um dos princípios basilares da administração pública é a supremacia dos interesses públicos sobre os interesses privados, que pode ser usada para afastar condenações de agentes políticos que, ainda que agindo contrariamente à lei, propiciem a efetividade do interesse público. Isso porque os princípios da responsabilidade fiscal e da responsabilidade social não podem ser antagônicos, tendo em vista que, mais do que responsabilidade, trata-se de obrigação realizar no presente os investimentos de melhoria para as gerações futuras, legando a elas os meios para pagar as dívidas assumidas em seu benefício. Há quem questione se. além da responsabilidade fiscal, que é muito importante, não deveria haver outra lei que punisse os governantes sem responsabilidade social (TEIXEIRA e CARVALHO, 2003:2), sendo esta última mais urgente (MERCADANTE, 2001:6).

\section{Considerações finais}

O ajuste fiscal é indispensável à economia e ao bem-estar social, diminuindo-se consequientemente a violência urbana, gerando a tão almejada e proclamada paz social.

As figuras penais inseridas em nosso ordenamento jurídico, relativas à gestão fiscal e responsabilização do administrador público como gestor do interesse público, trarão efetiva contribuição na tarefa de sensibilizar os titulares de cargos públicos quanto à importância da gestão fiscal responsável.

Por fim, endividamento não é sinônimo de irresponsabilidade fiscal.

Concluindo, a efetividade do Código Fiscal se deve, em grande parte, à possibilidade de criminalização pessoal dos administradores públicos que cometem tais abusos, subsumindo ao tipo legal. É por isso que se defendeu, no presente trabalho, 
como condição para a eficácia do controle da gestão fiscal, a existência e possibilidade de sanções pessoais ao administrador público.

Assim, uma das condições de eficácia social do código fiscal é a sanção dirigida de forma direta à pessoa do administrador público que comete a conduta infracional, não atingindo as sanções institucionais, pelo menos não de forma tão incisiva, tal fim, levando-se em conta o caráter preventivo e o repressivo da pena. A idéia é que o administrador público tem a obrigação de zelar pela res publica como se sua fosse, no interesse do bem-estar da coletividade, legitimando constantemente o mandato que lhe fora outorgado, concretizando-se assim a verdadeira democracia.

\section{Referência bibliográfica}

BRAGA, Marconi Augusto Fernandes de Castro [et. al.] (coord.). Lei de responsabilidade fiscal. In: Manual Básico do Tribunal de Contas de Minas Gerais. Belo Horizonte: dez.2000.

BRASIL, Decreto-lei $n^{\circ} 201$, de 27 de fevereiro de 1967. Dispõe sobre a responsabilidade dos prefeitos e vereadores, e dá outras providências. Disponível em http://www.planalto.gov.br. Acesso em 21/04/2003.

BRASIL, Decreto-lei $n^{\circ} 2.848$, de 07 de dezembro de 1940. Código Penal. Disponível em http://www.planalto.gov.br. Acesso em 21/04/2003.

BRASIL, Lei $n^{\circ} 1.079$, de 10 de abril de 1950. Define os crimes de responsabilidade e regula o respectivo processo de julgamento. Disponível em http://www.planalto.gov.br. Acesso em 21/04/2003.

BRASIL, Lei $n^{\circ} 10.028$, de 19 de outubro de 2000. Altera o Decreto-lei ${ }^{\circ} 2848 / 40$, a Lei $n^{\circ} 1079 / 50$ e o Decreto-lei $n^{\circ}$ 201/67. Disponível em http://www.planalto.gov.br. Acesso em 21/04/2003.

BRASIL, Lei Complementar $n^{\circ} 101$, de 04 de maio de 2000. Estabelece normas de finanças públicas voltadas para a responsabilidade na gestão fiscal e dá outras providências. Disponível em http://www.planalto.gov.br. Acesso em 21/04/2003.

CASTRO, Célio de. O desafio de romper a cortina de fumaça. In: Folha de São Paulo. São Paulo. 12.02.2001.

CASTRO, José Nilo de. Responsabilidade fiscal nos Municípios. Belo Horizonte. Del Rey, 2001.

FERRAZ JÚNIOR, Tercio Sampaio. Introdução ao estudo do direito: técnica, decisão, dominação. 2.ed. São Paulo. Atlas, 1994.

MERCADANTE, Aloizio. Outra lei. In: $O$ Globo. Rio de Janeiro. 17.03.2001.

MOREIRA NETO, Diogo de Figueiredo. A Lei de responsabilidade fiscal e seus princípios jurídicos. In: Revista de Direito Administrativo. Rio de Janeiro: Renovar, jul./set.2000. n.221.

MOTTA, Carlos Pinto Coelho e FERNANDES, Jorge Ulisses Jacoby. Responsabilidade fiscal: LC 101 de 04/05/2000. 2.ed. Belo Horizonte. Del Rey, 2001.

PRADO, Luiz Regis. Curso de direito penal brasileiro. v.4: parte especial: arts. 289 a 359-H. São Paulo. RT, 2001. 
QUADROS, Cerdônio e PALMIERI, Marcello Rodrigues (coord.). Lei de responsabilidade fiscal: Lei complementar $n^{\circ}$ 101, de 4/5/2000: Lei $n^{\circ}$ 10.028, de 19/10/2000: crimes contra as finanças públicas. São Paulo. NDJ, 2000.

QUEIROZ, Cid Heraclito de. A gestão fiscal responsável. In: Carta Mensal. Nov.1999. v.45. n.536.

A Lei de responsabilidade fiscal no contexto da reforma do Estado. In: Carta Mensal. Jan.2001. v.46. n.550.

ROCHA, Carmen Lúcia Antunes. Princípios constitucionais da administração pública. Belo Horizonte. Del Rey, 1994.

SANTANA, Jair Eduardo. Os crimes de responsabilidade fiscal tipificados pela Lei 10.028/2000 e a responsabilidade pessoal do administrador público. São Paulo. NDJ, 2001.

TEIXEIRA, Ana Claudia C. e CARVALHO, Maria do Carmo. Lei de responsabilidade fiscal. Disponível em http://www.polis.org.br/publicacoes/repente/integrarepente20011159.html. Acesso em 20/02/2003.

TOLEDO JR., Flávio C. de e ROSSI. Sérgio Ciquera. A Lei de responsabilidade fiscal e a tormentosa questão dos restos a pagar do Município. In: Boletim de Direito Administrativo. Dez.2001. v.17. n.12. 